\title{
Participatory design for community-based research: A study on regional student higher education pathways
}

Supporting higher education participation across equity groups has long been a directed effort in global higher education practice and policy. However, to date, there has been little improvement in the rates of Australian higher education participation by equity groups such as regional/remote, low socioeconomic, and Indigenous Australian students. In this study, we visited four outer-regional communities in Victoria, Australia to utilise participatory design methods as an approach to explore participants' ideas on the optimal nature of early stage higher education outreach interventions and how future resources or programs can be designed. Our case study of four schools showcases how participatory design with students (Year 7 and 8), school staff, and carers (e.g. family, community leaders) ( $\mathrm{n}=101$ ) helped to elicit participant feedback and ideas as well as support the subsequent codesign of future resources and outputs. Key findings included the need to address information gaps on the daily life of university students and the importance of context-specific advice and interventions.

Keywords: higher education, inequity and social justice, research design, participatory design, widening participation

\section{Introduction}

Universities have long been concerned with equitable access to help promote individual and community-level socioeconomic advancement and drive economic growth (Adnett 2016; Pitman 2017). More recently, the focus has turned to identifying and addressing structural inequalities in access and participation for groups of students, including those from regional backgrounds (Naylor and Mifsud 2020; Tight 2018). Shah, Bennett and Southgate (2015) have highlighted the need to create a sense of belongingness at university for students from regional and/or other equity groups as a means to recruit and retain these students. Participatory design methods have increasingly been identified as a means to foster and include communities in university outreach programs such as research and intervention processes (DiSalvo, Clement and Pipek 2012; Gannon and Naidoo 2020). Literature has suggested that participatory design methods can bolster community buy-in and help to ensure the full range of stakeholders can be engaged in the process (Lung-Amam and Dawkins 2019; Spinuzzi 2005).

In this study, we explored participants' ideas and suggestions on how to improve higher education participation among regional/rural, low socioeconomic and Indigenous students. To support our investigation, we utilised a participatory design methodology and hosted co-design workshops with 101 participants in four outer-regional schools in Victoria, Australia. The co-design workshops involved three stakeholder groups: students (Year 7 and 8), school staff (e.g. principals, teachers, career counsellors), and carers (e.g. parents, foster carers, family members, Indigenous leaders, community members). Consistent with participatory design methodology, our focus was to collect participant ideas and suggestions on how to design or support early-stage university outreach interventions. 
Our paper begins with an introduction into the context of widening participation in Australia and an overview of participatory design methodology. We then present our findings from four schools on how co-design methods helped us to explore the issue of improving higher education pathways in regional communities. Finally, we link our findings into the current widening participation context and offer recommendations for future policymaking and outreach intervention design and support.

\section{Widening participation: the historical and policy context}

Widening participation has been a higher education policy objective across the world, with a growing awareness that some groups are persistently under-represented. In the Unites States, scholars and policymakers have sought to raise the representation of African American, Latinx, Native American and, increasingly, Asian American, Native Hawaiian, and Pacific Islander communities (Jones, Jones, Elliott, Owens, Assalone and Gándara 2017). In the United Kingdom, class, race and gender have been emphasised, with a focus on increasing the participation of Black, Asian, and Minority Ethnic (BAME) students, those from low socio-economic backgrounds and more recently, white working-class boys (Atherton and Mazhari 2019). In Australia, widening participation has focussed on six identified equity groups: people from low socio-economic status (SES) backgrounds; regional and remote people; those from non-English speaking backgrounds or with a disability; Indigenous people; and women in non-traditional areas, such as Engineering and Informational Technology (Fray, Gore, Harris and North 2020; Harvey, Burnheim and Brett 2016). In recent years, scholars have also identified several other under-represented groups, such as carers, parents, first in family students, and people from out-of-home care backgrounds (Harvey, McNamara and Andrewartha 2015; Stone and O’Shea 2019).

In 2008, the Australian Labor Government supported a higher education review (known as the Bradley Review) which recommended the implementation of a demand-driven system, in which universities would receive funding for unlimited student places in most courses (Bradley, Noonan, Nugent and Scales 2008). The demanddriven funding system was thus introduced in 2010 alongside an ambitious growth target of $40 \%$ bachelor’s degree attainment among people aged 25-34 years old by 2025. Alongside the growth target, the Government also adopted the Bradley equity target, committing to $20 \%$ representation by students from the lowest socioeconomic quartile. Measures such as the Higher Education Participation and Partnership Program (HEPPP) were also introduced, which represented a ten-fold increase in dedicated equity funding (Brett and Harvey 
2019). HEPPP provided institutions with additional funding for outreach and support, allocated on the basis of institutional share of undergraduate students from low socioeconomic status (SES) backgrounds.

Under the Bradley reforms, overall participation in Australian higher education rapidly expanded by more than 30 \% (Department of Education and Training 2016). Yet, by the end of the demand-driven system in 2017, the low SES participation rate had risen only moderately, and regional participation has remained flat (Burnheim and Harvey 2016; Napthine, Graham, Lee and Wills 2019). Low SES, Indigenous, and regional students still today remain under-represented at university. In fact, the secondary school achievement gap between urban and rural Australia has widened in the past decade (Napthine et al. 2019). Scholars such as Welch (2007) and Nelson et al. (2017) have suggested much more needs to be done for regional and rural communities, including inclusive targeted programs that avoid deficit models. The lack of significant improvement in this area also points to a need for new methods, including more collaborative and participatory approaches, to help address ongoing participation barriers, as well as pervading stereotypes that university is only for select groups.

\section{Participatory design as an outreach and evaluation method}

Unlike traditional research methods that often seek to evaluate impact, participatory design methodology and its corresponding methods (sometimes known as toolkits) are primarily concerned with user-generated ideas and suggestions that can help design or improve existing services, programs, or resources. Elberse, CaronFlinterman and Broerse (2011) have identified three major rationales for engaging in participatory design methodologies: 1) increased quality of findings (whether in terms of depth, breadth or reliability); 2) addressing ethical concerns, that participants have the right to be involved in research that relates to them; and 3) to improve implementation, on the assumption that participant engagement may lead to better acceptance and application of findings. As participatory models can further build research and analytical capacity within local communities, the approach can potentially rectify long-term power imbalances and safeguard against future unethical or detrimental research methods (Hamington 2019).

The benefits of participatory design methods have been well documented in the literature and include building mutually beneficial goals across diverse stakeholders, reciprocal learning opportunities, supporting community empowerment, and the co-ownership of outcomes (see El Ansari 2005; McNally et al., 2017) Yet, participatory design is not without its challenges. Namely, there remain inconsistencies and vagueness around what 
constitutes 'participation' with scholars noting a range from consultation to participants taking a leading role (see Titterton and Smart 2008). In this study, participants were not involved in the initial research design (which was approved by university ethics and the Victorian Department of Education). Instead they were involved in the co-design of outputs which supports the integration of contextual knowledge and aids dissemination (Kelly, 2006). El Ansari (2005) also noted that in the healthcare sector five main challenges of participatory design include differing value systems between researchers and participants, stakeholders' costs and benefits of being involved, issues around empowerment, the need for multidisciplinary approaches, and more clarity in the roles and relationships between stakeholders. These issues were mitigated in our study through pre-arrival conversations with each school principal (or nominated staff contact), occurring at least 2 weeks before our scheduled visit (see guidance provided by Dell’Era and Landoni 2014; Sanders and Stappers 2014; Spinuzzi 2005). In these conversations, staff were asked to share their thoughts on the school context and community, while a member of the research team provided a list of workshop activities for approval and feedback. Following staff workshops at the schools, staff also had an opportunity to ask the research team questions and learn more about the study's goals and intended outcomes.

While the collaborative nature of participatory design can often help co-create solutions to issues better than a single design/evaluation team (Baek and Lee 2008), data collected from diverse groups (including pictures or drawings) have often been described as 'messy' and difficult to translate into words (see Frauenberger et al. 2015). Good practice of participatory design therefore stipulates the importance of developing specific research questions from the outset to help ensure organised data collection (Mahat, Grocott and Imms 2017). In this study we also aided analysis by having at least two researchers code and analyse data, as well as using memberchecking procedures with principals or lead-teachers at each of the schools to help validate our findings.

\section{Research Design and Sample}

In 2019-2020 the research team was awarded a grant from the National Centre of Student Equity in Higher Education (NCSEHE) to explore the perceptions of students, carers, and teachers’ needs and experiences towards higher education pathways. In particular, the study was focussed on improving resources to bolster higher education participation for low SES, outer-regional and/or Indigenous Australian communities. The sample for the study included four schools in outer-regional Victoria. Participants included Year 7 and 8 students, school staff, and carers ( $\mathrm{n}=101)$. While participants were not included in the initial research design, the 
overarching research questions sought to explore participants' ideas and suggestions on how future interventions or outreach programs could be designed and what resources would be useful to communities. Research questions included:

i. What is the optimal nature, delivery, and timing of early stage interventions (i.e. in Years 7 and 8) for students from equity groups?

ii. What resources can be co-designed with key stakeholders (e.g. teachers, carers, family) to support interventions and higher education pathways?

At the time of research (Term 1, 2020), 2019 student enrolment data were the most recent available (see Table 1). In 2019, students with primary residential addresses from outer-regional Victoria totalled 35,678, representing $3.6 \%$ of the total percentage of students, while the Australian percentage equated to $7.93 \%$ of the national student cohort. As Victoria is a predominantly urban area, 419 students were classified as 'Remote', with no 'Very Remote’ student populations.

Table 1. Contextualising Victoria: Geographical distribution of primary and secondary school students in Victoria

Several factors were considered to assist with identifying suitable schools that met the study's criteria. In the first instance, Victorian government schools located in areas classified as 'Outer Regional' by the Australian Statistical Geography Standard (ASGS) were shortlisted as possible candidates (ABS 2011). The selection process also acknowledged environmental factors, particularly the ramifications of the bushfires affecting communities along Australia's east coast in late 2019/early 2020. As a result, it was determined that schools located in areas affected by the bushfire, namely located in eastern Victoria, would be omitted from the study.

Schools were then evaluated according to the size of their student population and any high schools with fewer than 60 students (i.e. 10 students per year level) were also omitted from the shortlist (DET 2019). The extent of a school's Indigenous student representation was also a primary consideration during the selection process. Given students identifying as Aboriginal and/or Torres Strait Islander constitute 1.74\% of the Victorian student enrolments, schools with an Indigenous cohort of at least 2\% were preferred (ABS 2019). 
This study adopted the Index of Community Socio-Educational Advantage (ICSEA) as a means to ascertain the relative socio-educational advantage of each school community. The calculation equation for ICSEA values takes into account parents’ occupations, parents’ level of educational attainment, geographical location and proportion of Indigenous families per school to ascertain a school's level of educational advantage (ACARA 2013). The ICSEA value of a school is the average score as calculated by the equation, with schools in Australia ranging from about 500 to 1300 . The national mean value is 1000 , thus schools below that figure were considered low SES for the purposes of this study.

It is important to note that ICSEA is not a measure of SES and there are limitations to the index (for instance see Goss, Sonnemann and Emslie 2018). Principals have expressed concerns that other data based on Student Family Occupation (SFO) and Education Maintenance Allowance (EMA) recipients could contradict ICSEA values (APPA 2010). Other equity areas not considered in the calculation of index values include students from non-English speaking backgrounds, new arrivals, or students’ home circumstances all of which can affect educational advantage. The intersectionality of disadvantage in education, and its compounding effects, is wellunderstood (see Tefera et al. 2018), yet such data about Australian students are not yet publicly available.

A total of 26 schools in Victoria matched our study's criteria. After sending email and/or placing phone calls to schools, four schools from outer-regional Victoria were recruited to participate in co-design workshops. All participating schools from Victoria held ICSEA values below 1000 and at least 2\% Indigenous student enrolment, with the schools located in areas classified as 'Outer Regional’ (Table 3). Please note, schools have been renamed to protect their privacy.

Table 2. Demographics related to participating schools according to APPA (2019)

Schools were sent information and consent forms prior to the research team's arrival. Schools worked with teachers and guardians to ensure all students' consent forms were completed prior to the workshops taking place. If one or more of the students who completed mandatory consent forms had an Indigenous background a Koorie Engagement Support Officer (KESO) was invited by the principal to attend the workshops (occurring in SV1 and SV4). However, no students were singled out or excluded during any workshop activities. Further, 
gender was balanced across student participants with 27 male students and 24 female students, all 5 carers we spoke to were female, as were the majority of the school staff (22 females compared to 8 males).

\section{Participatory Design Workshops}

To support participatory methodology the approach of the study involved holding three co-design workshops at each of the four selected schools, one for students (Year 7 and 8), one for school staff, and one for carers (e.g. parents, community members). Each workshop was between 60-90 minutes in duration, depending on the schedule availability of the school, and utilised a range of co-design methods to elicit participants' experiences, perceptions, and ideas. All activities (see Table 3) related to a specific research question of the study. Participants in each workshop were asked to participate in all activities.

As can be seen from Table 3 below the participatory design activities differed from typical interview or focus group style questions by their multi-layered approach to uncovering perceptions and helping support ideation. A key aspect of participatory design activities is that they provide a scaffolded approach to aid participants’ critical thinking. To illustrate, we first asked student participants to participate in a 'flash thinking' exercise aimed to get students to share what words came to mind when they thought about university. This exercise helped students begin to focus on what perceptions and stereotypes they had of universities. Expanding from that we then asked students to vote with flashcards about common support or advice they had received about university, further unpacking their perceptions of and experiences with higher education. Through a scaffolded approach, we then built on the responses from these activities to generate students' ideas about what should be included in an intervention program, such as what activities and/or guest speakers. Other techniques used included storyboarding, where participants drew a series of sequential scenes depicting an event or staged process, and role-playing, where participants took on a different role from their own (i.e. a student playing a teacher) to depict an ideal conversation or learning activity. In all of these various activities, the intended goal was not only to collect data from participants but to help participants reflect on their own experiences as well. Participatory design methods such as these are both a research tool and an intervention program, designed to integrate theory and practice to respond to a research question (Dollinger \& Vanderlelie, 2020; Mahat et al. 2017). For a full overview of the participatory design activities we used, please refer to our handbook (Dollinger \& D’Angelo, 2020). 


\section{Table 2. Detailed Example of Student Participant Workshop Activities}

Data from workshops, either verbal (via audio-recordings), observational (via field notes), or written (e.g. voting tallies, worksheets, sticky notes) were recorded, transcribed (if necessary), and analysed using thematic analysis. It is important to note that in some cases, workshops were facilitated by teachers or local Indigenous representatives from the area upon request from the school. The thematic analysis methods allowed for emergent themes to arise from the data through pattern finding (Fereday and Muir-Cochrane 2006). As mentioned previously, all data were checked and re-coded by at least two members of the research team and member-checked with a representative from the school, typically the school principal.

\section{Major Findings from Participatory Design Research}

In this section we first discuss the major findings resulting from participants' ideas on the optimal nature of interventions and subsequently discuss how these findings later informed and helped the research team to codesign resources for the regional communities we visited in Victoria.

\section{Participant ideas on the optimal nature of interventions}

Our first research question was aimed to explore participants' ideas on the optimal nature, delivery, and timing of early stage interventions. Previous studies have highlighted that regional students may feel anxious about choosing between postsecondary education options and the potential of leaving their community (O'Shea 2016; Vernon, Watson and Taggart 2018) so we sought to conduct activities that would help uncover specifically what information students would like to know to help mitigate questions and concerns. Several co-design activities were included within workshops to help elicit these ideas, including students planning a 'Learn About University Day’ as well as a timeline activity where adult participants (teachers, carers) mapped out when and how interventions would take place and what they would include or consist of (e.g. mentoring, trips, information, guest speakers, etc.).

Arising from all workshops was a stressed desire for early stage interventions to focus more explicitly on the daily life of university students. In particular, the students had a range of questions that were recorded through the 'Learning about University Day' activity where, in groups, they pitched their ideas on potential 
content or learning activities. Questions they suggested, which can continue to be addressed in outreach intervention programs, included:

- What is food like at university? Where can you buy food and what kind of food can you buy? Do I have to buy food from the canteen?

- What is it like to sit in a lecture? How do university students do experiments? What can you expect from your subjects? What do most people study?

- What does a university campus look like? How many people are in one class?

Fundamentally, this activity was designed to encourage students to identify where the gaps of current interventions or information were, rather than provide feedback on the quality of services (e.g. through a Likertscale survey question). While some of the students' questions are already addressed in existing outreach programs (see Fleming and Grace 2014), it is possible that supporting student agency to feel included in the design may increase engagement and impact. We also ran a similar version of this activity with adult participants, including school staff. School staff also voiced many questions and concerns over current information available including differences between postsecondary options, alternative pathways into university for low ATAR students, how to make university work if your family doesn't support you, statistics on the cost of university compared to future earnings, and more information on what life after university may look like for students (SV1, SV2, SV3, SV4). They also frequently mentioned that parents or carers were critical in helping them support students towards higher education pathways and they should be more directly included within early stage interventions (see similar recommendations from Fray et al. 2020; Smith, Trinidad and Larkin 2015). As one carer in SV2 commented, "A lot of people think universities have nothing to offer... parents who haven’t been to university don’t push it much”. Participants felt that any intervention or resource would need to clearly articulate the benefits of a university in terms of what jobs require a university degree or expected lifetime earnings.

Across our workshops, school staff and carers also frequently noted that optimal interventions for higher education pathways should begin 'planting the seed' as early as primary school. They suggested foundational activities where teachers could ask students, "Do you know how someone becomes a....” (SV1). However, most felt that more directed careers/pathways interventions should begin in Year 7 and Year 8, where students are 
offered opportunities to participate in excursions with overnight stays, visit local business places or organisations to see what work is available in town, and perhaps be matched with regional student mentors who are current university students. It is interesting to note that in only two of the workshops (SV1, SV4) did the discussion of regional universities or campuses arise. In both instances, adult participants felt that students should be made aware of the differences between studying at a regional campus compared to a metropolitan campus. One carer in SV4 noted, "Regional campuses are letting us down, the quality at [anonymised regional campus] isn't the same.” A similar sentiment was communicated when it came to online study as well, with a school staff in SV3 commenting, "Online courses are not real courses, how can you learn to be a teacher online?” These findings highlighted a need to better communicate the benefits and the drawbacks to regional and/or online study to regional communities.

Participants also shared with us how future early stage interventions could be designed to improve engagement or satisfaction among regional communities. To exemplify, one suggestion from Site Visit 2 was called 'Make it Real' camp. School staff pitched a fully funded camp that would help both students and school staff learn about university and careers education. Students and teachers would visit a metropolitan university for 2 days in Year 8 (and a longer visit in Year 10) where they would stay in residence halls. Students on day one would be paired with a university student from a regional area studying in the same discipline as they may wish to study one day. They would also go through a series of tutorials on topics such as: budgeting, self-defence, co-curricular programs offered at the university, and public transport information. At the end of the visit there would be a trivia night to test students on the information they’ve learned. As the students go through the tutorials, school staff would also be exposed to professional development on topics such as, alternative pathways to higher education, navigating university websites, student support services available, and introduction to careers education.

As co-design methods are designed to elicit participants' feelings and emotions linked to their experiences (Sanders 1998) we also found that adult participants were dissatisfied with their current relationships with universities. None of the schools had formal partnerships with universities and participants commented that they only received occasional or one-off visits. From our workshops with school staff and carers, it became clear that many felt that there were not enough community-driven or context-specific opportunities to support students towards higher education pathways. In particular, adults felt that career aspirations and learning needed to be 
tailored to the local jobs and needs of the community and include work forecasts for regional areas. They also felt that mentorship programs would best be delivered through local community mentors or at least mentors from other outer-regional areas. Through many of these discussions, participants felt that “....universities need to lead the effort in outreach" (SV2).

In one activity school staff and carers were asked to write down three wishes they would ask of the Prime Minister related to improving higher education pathways for regional students. Common themes emerging from this exercise included 'providing safe and affordable regional transport for students', 'more information about work trends in the local communities' and travelling roadshows of specialists coming to visit schools. Also of interest, school staff in this exercise frequently noted that they did not want to be asked to integrate any new topics into the existing curriculum. Staff also felt strongly that if a staff member (such as a teacher) wanted to take on additional careers education guidance work they should be compensated, as one teacher commented, “Please don’t ask me to add anything else to my teaching duties” (SV1 Staff) (echoing similar teacher sentiments captured by Stroud, 2016). And yet some school staff did believe that they needed more professional development on careers education, with one teacher saying the current offering of two per year wasn't enough and that the information was not localised enough. They noted that the Victorian Curriculum had no career subject and that the local college (100 kilometres away) held some events but it was inconvenient to attend (SV3 Staff).

Linking to the discussion of the need for more context-specific interventions and resources, some participants also voiced concerns over regional students leaving their communities. For example, in a discussion with a teacher she commented that one reason she does not recommend urban universities is that she perceived they 'push study abroad' (SV2 Staff). She mentioned, “I don’t want my students leaving Australia, we need to strengthen our nation”. A parent from the same community observed that “...country kids are naive about city life, why would I want to put that stress on them?” as she noted that their community had very low unemployment and there were many farming jobs available. Although several universities operate regional campuses in Victoria, the prospect of attending even regional cities was daunting to many students, their carers and teachers. Many adult participants felt that future interventions and resources should primarily highlight what a student can do with a university degree within their own community before assuming that the student must live in a metropolitan area post-graduation. 


\section{Co-designed resources with participants}

As stated in our research questions, we first sought to collect participants’ ideas on the optimal nature of interventions and resources, and then to harness this data and additional feedback into co-designing resources that would address these gaps (i.e. translate findings into relevant outputs). While several major outputs have been co-designed as a result of the study, including careers-orientated learning activities, intervention program ideas, and a template for university-school partnership agreement, we will focus here on how participants’ ideas and suggestions helped to inform and co-design a toolkit intended for school staff and carers.

To illustrate how we translated our findings, one of the main ideas resulting from the workshops was that early stage interventions should focus on providing information about the daily life of university students. In response, our toolkit resource included the questions posed by participants (what a lecture is like, etc) into a set of FAQs, answered by current regional university students. We also included a gamified version of the FAQs that adults could play with students to help demystify university life.

Another key aspect of the co-designed toolkit was to ensure we addressed participants suggestions around explicitly comparing postsecondary educational options (Technical and Further Education, online study, regional university) across key factors such as cost, potential earning, and types of available courses. In particular, adults stressed the importance of distinguishing between the Victorian Certificate of Education (VCE) and the Victorian Certificate of Applied Learning (VCAL), as well as information on apprenticeships and vocational educational options. As one of the main concerns from carers was around the safety of public transport (both in the city but also connecting regional communities to urban areas), we also provided a list of nearby universities and various transport options for students (as of current).

Above all, participants most frequently requested clarification about regional-specific, and ideally Victorianspecific, jobs information. This finding underpins previous research highlighting the importance of positive regional narratives (O’Shea et al. 2019; Roberts 2014; Ronan 2020). School staff and carers alike wanted to know where future skill shortages would be and what would likely be the key areas for regional employment sectors. Linked to our findings from the nature of optimal early stage interventions, adult participants felt that university pathways promotion should stress to students that they don't need to leave their local communities 
permanently just because they've decided to attend university. As such another aspect we included within the toolkit was a section on location independent jobs.

\section{Conclusion}

Increasing access and participation in higher education for regional/remote, low SES and Indigenous students has proved to be an intractable problem, as demonstrated by flat or declining university participation rates for these groups. This trend has persisted despite significant policy focus and expenditure by both government and universities over several decades (Berger, Holmes, Gore and Archer 2019; Napthine et al. 2019). These trends demonstrate the need for new collaborative, context-specific approaches to widening participation, in which under-represented students and communities are more engaged and empowered, and distinct community factors are deeply considered (see Welch, Helme and Lamb 2007).

In the study presented here, we expanded on previous research that has suggested a necessity to focus both on early stage interventions to drive meaningful change (Fleming and Grace 2014; Gannon and Naidoo 2020; Galliott and Graham 2015; Gore et al. 2017), as well as calls for future resources and interventions to be coinformed by participants and communities (Fray et al. 2020; O’Toole and Due 2015). We sought to shift participants from the objects of research to the ‘co-producers' (Abebe 2009). Through a series of co-design activities (e.g. mind maps, role-playing) participants helped us identify current information gaps about university and provide ideas and suggestions on how early stage interventions could be more successful to address those gaps. Major findings and participant ideas included the provision of more information on the daily lives of university students, comparisons across postsecondary educational options, and context-specific information and advice for future jobs and those which were location independent. Participants also expressed the importance of embedding a positive narrative about regional life and career opportunities, linking to previous findings that dominant educational discourses too often marginalise rural areas (see Corbett 2007; Roberts 2014). Interestingly, there was also a finding, which merits future exploration, that some participants held negative perceptions about regional and/or online study options. To overcome this, explanation of the benefits and drawbacks to these study options was also included within subsequent co-designed outputs, such as the toolkit for school staff and carers. 
Our study here has provided a translatable example of how co-design methods can be used to elicit participant feedback to help co-design resources. While here we have discussed how their ideas helped to inform a toolkit, participants ideas also helped to inform learning activities, intervention programs, and a template for a university-school partnership agreement. Future research could investigate how participatory design helps to support democratic community-based research (see Hooley, 2005) and whether it leads to later increased uptake or usage of community-informed outputs. In the future, it would also be useful to continue to expand how participants can be positioned as 'co-researchers' which would include how to support participants in the initial conceptualisation of research projects, designing research questions, and jointly creating intervention or pilot programs.

While many higher education reviews and studies seek to capture the voices of students, few have incorporated principles of co-design, such as reciprocal learning opportunities, and seeking ideas and solutions over feedback. Yet through participatory design, participants are empowered to help co-create solutions to ongoing issues that can help support good practice and meaningful change. Napthine et al. (2019) recommended in their research that when working with marginalised communities it is important to adhere to the notion of 'nothing about us without us', and it is our hope here that this notion continues to be expanded in educational research.

\section{Declarations}

Funding:

This work was supported by the National Centre for Student Equity in Higher Education (NCSEHE).

Conflict of interest:

Not applicable

Availability of data and material:

Upon request

Code availability:

Not applicable

\section{References}

Abebe, T. (2009). Multiple methods, complex dilemmas: negotiating socio-ethical spaces in participatory research with disadvantaged children. Children's Geographies, 7(4), 451-465.

https://doi.org/10.1080/14733280903234519

ABS (Australian Bureau of Statistics). (2011). Australian Standard Geographical Classification (ASGC). Australian Government.

https://www.abs.gov.au/websitedbs/D3310114.nsf/home/Australian+Standard+Geographical+Classification+(A $\underline{\text { SGC) }}$ 
ABS (Australian Bureau of Statistics). (2019). Estimates and projections, Aboriginal and Torres Strait Islander Australians, 2006 to 2031, 3238.0. Australian Government.

https://www.abs.gov.au/AUSSTATS/abs@.nsf/DetailsPage/3238.02006\%20to\%202031?OpenDocument

ACARA (2013). Australian Curriculum, Assessment and Reporting Authority. Guide to understanding 2013

Index of Community Socio-educational Advantage (ICSEA) values.

www.acara.edu.au/verve/_resources/Guide_to_understanding_2013_ICSEA_values.pdf

Adnett, N. (2016). The economic and social benefits of widening participation: rhetoric or reality?. In Shah, M., Bennett, A., Southgate, E. (Eds.), Widening Higher Education Participation. (pp. 211-224). Chandos Publishing. https://doi.org/10.1016/B978-0-08-100213-1.00013-5

APPA (Australian Primary Principals Association). (2010). My School Website: Report on APPA member views. https://www.appa.asn.au/policy-and-media/past-reports/

Atherton, G. \& Mazhari, T. (2019). Working Class Heroes - Understanding access to higher education for white students from lower socio-economic backgrounds: A National Education Opportunities Network (NEON) report, UK. https://www.educationopportunities.co.uk/wp-content/uploads/Working-Class-HeroesUnderstanding-access-to-Higher-Education-for-white-students-from-lower-socio-economic-backgrounds.pdf

Baek, J. S., \& Lee, K. P. (2008). A participatory design approach to information architecture design for children. Co-Design, 4(3), 173-191. https://doi.org/10.1080/15710880802281026

Berger, N., Holmes, K., Gore, J. M., \& Archer, J. (2019). Charting career aspirations: a latent class mixture model of aspiration trajectories in childhood and adolescence. The Australian Educational Researcher, 1-28. https://doi.org/10.1007/s13384-019-00363-x

Bonevski, B., Randell, M., Paul, C., Chapman, K., Twyman, L., Bryant, J., ... \& Hughes, C. (2014). Reaching the hard-to-reach: a systematic review of strategies for improving health and medical research with socially disadvantaged groups. BMC medical research methodology, 14(1), 42. https://doi.org/10.1186/1471-2288-14-42

Bradley, D., Noonan, P., Nugent, H., \& Scales, B. (2008). Review of Australian Higher Education: Final Report. Canberra. http://hdl.voced.edu.au/10707/44384.

Brett, M. \& Harvey., A. (2019) Advancing Equity in the Australian Higher Education System. In James, R., French, S. \& Kelly, P. (Eds), Visions for Australian Tertiary Education, Centre for the Study of Higher Education, Melbourne, pp.77-90. ISBN: 978-0-7340-5341-1

Burnheim, C. \& Harvey, A. (2016). 'Far from the studying crowd? Regional and rural Australians in higher education'. In A. Harvey, C. Burnheim and M. Brett (Eds.), Student Equity in Australian Higher Education: Twenty-five Years of a Fair Chance for All. Singapore: Springer Publishing. ISBN 978-981-10-0315-8

Corbett, M. (2007). Learning to leave: The irony of schooling in a coastal community. Canada: Fernwood Publishing.

Dell'Era, C., \& Landoni, P. (2014). Living lab: A methodology between user-centred design and participatory design. Creativity and Innovation Management, 23(2), 137-154. https://doi.org/10.1111/caim.12061

Department of Education and Training (2016). uCube - Higher education statistics. Canberra: Department of Education and Training. http://highereducationstatistics.education.gov.au/Help.aspx

DET 2019. State of Victoria: Department of Education and Training. (2019). Victorian Schools: Summary statistics July 2019, viewed 6 April 2020, http://www.education.vic.gov.au/about/department/Pages/factsandfigures.aspx

DiSalvo, C., Clement, A., \& Pipek, V. (2012). Communities: Participatory Design for, with and by communities. In Simonsen, J. \& Robertson, T. (Eds.)., Routledge International Handbook of Participatory Design (pp. 202-230). Routledge. https://doi.org/10.4324/9780203108543 
Dollinger, M. \& D’Angelo, B. (2020). Co-Design for Student Success. National Centre for Student Equity in Higher Education. https://www.ncsehe.edu.au/wp-content/uploads/2020/03/CoDesignHandbook_FINAL.pdf

Dollinger, M., \& Vanderlelie, J. (2020). Closing the loop: co-designing with students for greater market orientation. Journal of Marketing for Higher Education, 1-17. https://doi.org/10.1080/08841241.2020.1757557

El Ansari, W. (2005). Collaborative research partnerships with disadvantaged communities: challenges and potential solutions. Public Health, 119(9), 758-770. https://doi.org/10.1016/j.puhe.2005.01.014

Elberse, J. E., Caron-Flinterman, J. F., \& Broerse, J. E. (2011). Patient-expert partnerships in research: How to stimulate inclusion of patient perspectives. Health Expectations, 14(3), 225-239. https://doi.org/10.1111/j.13697625.2010.00647.x

Fereday, J., \& Muir-Cochrane, E. (2006). Demonstrating rigor using thematic analysis: A hybrid approach of inductive and deductive coding and theme development. International Journal of Qualitative Methods, 5(1), 8092. https://doi.org/10.1177/160940690600500107

Fleming, M. J., \& Grace, D. M. (2014). Increasing participation of rural and regional students in higher education. Journal of Higher Education Policy and Management, 36(5), 483495. https://doi.org/10.1080/1360080X.2014.936089

Frauenberger, C., Good, J., Fitzpatrick, G., \& Iversen, O. S. (2015). In pursuit of rigour and accountability in participatory design. International Journal of Human-Computer Studies, 74, 93-106. https://doi.org/10.1016/j.ijhcs.2014.09.004

Fray, L., Gore, J., Harris, J., \& North, B. (2020). Key influences on aspirations for higher education of Australian school students in regional and remote locations: a scoping review of empirical research, 19912016. The Australian Educational Researcher, 47(1), 61-93. https://doi.org/10.1007/s13384-019-00332-4

Galliott, N., \& Graham, L. J. (2015). School based experiences as contributors to career decision-making: findings from a cross-sectional survey of high-school students. The Australian Educational Researcher, 42(2), 179-199. https://doi.org/10.1007/s13384-015-0175-2

Gannon, S., \& Naidoo, L. (2020). Thinking-feeling-imagining futures through creative arts-based participatory research. The Australian Educational Researcher, 47(1), 113-128. https://doi.org/10.1007/s13384-019-00330-6

Gore, J., Holmes, K., Smith, M., Fray, L., McElduff, P., Weaver, N., \& Wallington, C. (2017). Unpacking the career aspirations of Australian school students: Towards an evidence base for university equity initiatives in schools. Higher Education Research \& Development, 36(7), 1383-1400.

https://doi.org/10.1080/07294360.2017.1325847

Goss, P., Sonnemann, J., and Emslie, O. (2018). Measuring student progress: A state-by-state report card. Grattan Institute. https://grattan.edu.au/report/measuring-student-progress/

Hamington, M. (2019). Integrating care ethics and design thinking. Journal of Business Ethics, 155(1), 91-103. http://link.springer.com/10.1007/s10551-017-3522-6

Harvey, A., Andrewartha, L., \& McNamara, P. (2015). A forgotten cohort? Including people from out-of-home care in Australian higher education policy. Australian Journal of Education, 59(2), 182-195.

https://doi.org/10.1177/0004944115587529

Harvey, A., Burnheim, C., \& Brett, M. (2016). Towards a fairer chance for all: Revising the Australian student equity framework. In Harvey, A., Burnheim, A., Brett, C. (Eds.), Student Equity in Australian Higher Education (pp. 3-20). Springer, Singapore.

Hooley, N. (2005). Participatory action research and the struggle for legitimation. The Australian Educational Researcher, 32(1), 67-82. https://doi.org/10.1007/BF03216813 
Jones, T., Jones, S. M., Elliott, K. C., Owens, L. R., Assalone, A. E., \& Gándara, D. (2017). Outcomes based funding and race in higher education: Can equity be bought? Palgrave Macmillan. Cham, Switzerland. https://doi.org/10.1007/978-3-319-49436-4

Kelly, A. E. (2006). Quality criteria for design research. Educational Design Research, 107-118.

Koshy, P., Dockery, A. M., \& Seymour, R. (2019). Parental expectations for young people’s participation in higher education in Australia. Studies in Higher Education, 44(2), 302-317.

Lung-Amam, W. S., \& Dawkins, C. (2019). The power of participatory story mapping: Advancing equitable development in disadvantaged neighbourhoods. Community Development Journal.

https://doi.org/10.1093/cdj/bsy064

Mahat, M., Grocott, L., \& Imms, W. (2017). “In the real world...”: Teachers’ perceptions of ILEs. ILETC phase 1 teacher workshops. Melbourne: University of Melbourne. Retrieved from: http://www.iletc.com.au/publications/reports/

McNally, B., Mauriello, M. L., Guha, M. L., \& Druin, A. (2017, May). Gains from participatory design team membership as perceived by child alumni and their parents. In Proceedings of the 2017 CHI Conference on Human Factors in Computing Systems (pp. 5730-5741). https://doi.org/10.1145/3025453.3025622

Napthine, D., Graham, C., Lee, P. \& Wills, M. (2019). National Regional, Rural and Remote Tertiary Education Strategy - final report. Commonwealth of Australia. https://docs.education.gov.au/documents/national-regionalrural-and-remote-tertiary-education-strategy-final-report

Nelson, K., Picton, C., McMillan, J., Edwards, D., Devlin, M., \& Martin, K. (2017). Understanding the completion patterns of equity students in regional universities. Perth, WA: National Centre for Student Equity in Higher Education (NCSEHE), Curtin University.

Naylor, R., \& Mifsud, N. (2020). Towards a structural inequality framework for student retention and success. Higher Education Research \& Development, 39(2), 259-272. https://doi.org/10.1080/07294360.2019.1670143

O'Shea, S. (2016). Avoiding the manufacture of 'sameness': First-in-family students, cultural capital and the higher education environment. Higher Education, 72(1), 59-78.

O’Shea, S., Southgate, E., Jardine, A. \& Delahunty, J. (2019). 'Learning to leave’ or 'striving to stay': Considering the desires and decision of rural young people in relation to post- schooling futures. Emotion, Space and Society, 32, 1-8.

O’Toole, N., \& Due, C. (2015). School engagement for academically at-risk students: A participatory research project. The Australian Educational Researcher, 42(1), 1-17. https://doi.org/10.1007/s13384-014-0145-0

Pitman, T. (2017). Widening participation in higher education: a play in five acts. Australian Universities' Review, 59(1), 37-46. ISSN-0818-8068.

Roberts, P. (2014). A curriculum for the country: The absence of the rural in a national curriculum. Curriculum Perspectives, 34(1), 51-60.

Ronan, C. (2020). “Should I stay, or should I go?”: The mobility paradigm in widening participation for regional, rural and remote students. International Students in Widening Participation, 7(1), 34-47.

Sanders, E. B. N., \& Stappers, P. J. (2014). Probes, toolkits and prototypes: three approaches to making in codesigning. CoDesign, 10(1), 5-14. https://doi.org/10.1080/15710882.2014.888183

Seedat, M., Suffla, S., \& Christie, D. J. (Eds.). (2017). Emancipatory and participatory methodologies in peace, critical, and community psychology. Springer. Cham, Switzerland. DOI: 10.1007/978-3-319-63489-0

Shah, M., Bennett, A., \& Southgate, E. (2015). Widening higher education participation: A global perspective. Chandos Publishing, Waltham, MA. ISBN: 978-0-08-100213-1. 
Smith, J., Trinidad, S., \& Larkin, S. (2015). Participation in higher education in Australia among underrepresented groups: What can we learn from the Higher Education Participation Program to better support Indigenous learners?. Learning Communities: Internal Journal of Learning in Social Contexts: Special Edition: Indigenous Pathways and Transitions into Higher Education, 17, 12-29.

Spinuzzi, C. (2005). The methodology of participatory design. Technical Communication, 52(2), 163-174.

Stone, C., \& O'Shea, S. (2019). Older, online and first: Recommendations for retention and success. Australasian Journal of Educational Technology, 35(1). https://doi.org/10.14742/ajet.3913

Stroud, G. J. (2016). Teaching Australia: Fight or flight?. Griffith Review, (51), 228. ISSN: 1839-2954

Tefera, A.A., Powers, J.M., Fischman, G.E. (2018). Intersectionality in education: A conceptual aspiration and research imperative. https://doi.org/10.3102/0091732X18768504

Tight, M. (2018). Higher education research: The developing field, Bloomsbury Publishing, New York, USA. ISBN: 978-1-4742-8373-1

Titterton, M., \& Smart, H. (2008). Can participatory research be a route to empowerment? A case study of a disadvantaged Scottish community. Community Development Journal, 43(1), 52-64.

https://doi.org/10.1093/cdj/bsl037

Vernon, L., Watson, S. J., \& Taggart, A. (2018). University aspirational pathways for metropolitan and regional students: Implications for supporting school-university outreach partnerships. Australian and International Journal of Rural Education, 28(1), 87.

Welch, A. (2007). The city and the bush. In R. Connell, C. Campbell, M. Vickers, A. Welch, D. Foley, \& N. Bagnall (Eds.), Education, change \& society (pp. 70-93). Melbourne, Australia: Oxford University Press.

Welch, A., Helme, S., \& Lamb, S. (2007). Rurality and Inequality in Education. In International studies in educational inequality, theory and policy (pp. 602-624). Springer, Dordrecht. https://doi.org/10.1007/978-14020-5916-2_25 


\section{University Library}

\section{- M M N E R VA A gateway to Melbourne's research publications}

Minerva Access is the Institutional Repository of The University of Melbourne

Author/s:

Dollinger, M;D'Angelo, B;Naylor, R;Harvey, A;Mahat, M

Title:

Participatory design for community-based research: a study on regional student higher education pathways

Date:

2020-11-20

Citation:

Dollinger, M., D'Angelo, B., Naylor, R., Harvey, A. \& Mahat, M. (2020). Participatory design for community-based research: a study on regional student higher education pathways. AUSTRALIAN EDUCATIONAL RESEARCHER, 48 (4), pp.739-755. https://doi.org/10.1007/ S13384-020-00417-5.

Persistent Link:

http://hdl.handle.net/11343/252705 